\title{
Results of the Evaluation of the Respiratory Condition of Permanent Workers in an Oil Mill in Benin
}

\author{
Mênonli Adjobimey1,2* (D), Vikkey Hinson1, Serge Ade ${ }^{3}$, Rose Mikponhoue ${ }^{1}$, Ibrahim Mama Cisse ${ }^{4}$, \\ Amélé Adjogou', Véronique Dossougbété5, Paul Ayélo ${ }^{1}$
}

\author{
${ }^{1}$ Research and Teaching Unit in Occupational and Environmental Health FSS, Cotonou, Benin \\ ${ }^{2}$ Occupational Health Service of the National University Hospital of Pneumo-Phtisiology of Cotonou, Cotonou, Benin \\ ${ }^{3}$ Pneumology Unit, Faculty of Medicine, University of Parakou, Parakou, Benin \\ ${ }^{4}$ Occupational Health Training and Research Unit, Faculty of Medicine, Parakou, Benin \\ ${ }^{5}$ Louis Pasteur Clinic, Porto Novo, Benin \\ Email: ^menoladjobi@yahoo.fr
}

How to cite this paper: Adjobimey, M., Hinson, V., Ade, S., Mikponhoue, R., Cisse, I.M., Adjogou, A., Dossougbété, V. and Ayélo, P. (2022) Results of the Evaluation of the Respiratory Condition of Permanent Workers in an Oil Mill in Benin. Occupational Diseases and Environmental Medicine, 10, $1-12$.

https://doi.org/10.4236/odem.2022.101001

Received: October 3, 2021

Accepted: December 12, 2021

Published: December 15, 2021

Copyright $\odot 2022$ by author(s) and Scientific Research Publishing Inc. This work is licensed under the Creative Commons Attribution International License (CC BY 4.0).

http://creativecommons.org/licenses/by/4.0/

\begin{abstract}
Introduction: The process of extracting oil from cotton seeds can create dusty work atmospheres that can cause respiratory problems. The main objective of this study was to determine the prevalence of respiratory problems among permanent workers in an oil mill in Benin. Methods: This cross-sectional study of 52 workers in an oil mill took place in January 2017 as part of the annual medical check-ups of workers. A questionnaire was administered and spirometry using Spirobank II and chest radiography were performed. The spirometry results were interpreted by an occupational physician and a pulmonologist. Data were entered and analyzed using Epidata software. Results: The mean age was $42.7 \pm 6.4$ years, and 43 of the 52 workers were men. Of these, $58 \%$ were in technical production positions and $42 \%$ in administrative positions. Most of them had more than 10 years of seniority. The prevalence of respiratory symptoms among production workers was $4(13 \%)$ versus 2 (9\%) among administrative workers. A total of 8 (15.4\%) abnormal spirometry was identified with 4 obstructive syndrome, 3 restrictive syndrome, 1 a mixed pattern. There were $5(16.6 \%)$ workers in production versus $3(13.6 \%)$ in administration who had abnormal spirometry. The means $25 / 75$ forced expiratory flow (FEF) value of production workers was significantly lower than that of administration workers. Abnormal chest radiographs were 5 (17\%) in production workers compared to $3(14 \%)$ in administration workers. Conclusion: Oil mill workers had few respiratory symptoms. However, production workers had more ventilatory disorders than administrative workers. A spirometric follow-up of this group of workers is therefore necessary.
\end{abstract}


Keywords

Cottonseed, Oil Mill, Respiratory Symptoms, Spirometry, Chest Radiography, Benin

\section{Introduction}

The cotton industry employs thousands of workers in several countries around the world who are also exposed to various occupational hazards depending on the company's mission, the position held and the measures of prevention in place. Occupational exposure to dusts and gases can impair lung function [1]. Numerous studies have shown the effects of cotton dust on lung function in cotton mill and cotton gin workers [2] [3]. However, there are few data on the prevalence of respiratory disorders in non-textile industries such as cotton oil mills, where high levels of dust exposure have been demonstrated [4] [5]. Indeed, cotton seeds from the ginning process are sent to oil mills for oil extraction after processing. In general the production process of cottonseed oil can be summarized as follows: weighing and storage of cotton seeds, ginning, cooking, pressing, flattening, flaking, extraction, neutralization, decolorization, deodorization, storage of oil in bulk, storage in drums, storage of packaged oil, granulation, bagging, storage of cake in bags. This process generates a considerable amount of dust in the working environment and exposed to chemicals [4]. A study by Bakirci $\mathrm{N}$ et al. showed a variation in the ventilation function of workers before and after shift work in cottonseed oil mills in Turkey and the influence of smoking like the main risk factor for having respiratory symptoms [6]. Jones et al. showed similar results [7]. The main end products from seed processing are oil for human consumption, shells for farm animal feed and lint as an industrial source of paper and cellulose. During extraction, chemicals such as solvents are used that increase the respiratory risk for some workers assigned to these specific tasks [8]. Hexane is the most commonly used solvent for these operations. In addition to lung irritation on acute exposure, n-hexane can cause ventilatory disorders on sub chronic exposure [9]. Benin is one of the main exporters of cotton in West Africa and has several ginning mills and two cottonseed oil mills and cottonseed oil is very present in Beninese cuisine. Respiratory symptoms prevalence in textile workers was $36.9 \%$ [10] and in ginning mill ventilator troubles prevalence was (26.9\%) [11] but data are not available on respiratory disorders in cottonseed oil mills. The main objective of this study was to determine the prevalence of respiratory problems in workers in one cottonseed oil mill in the south of Benin.

\section{Materials and Methods}

\subsection{Study Design}

This is a cross-sectional-sectional study of 52 permanent workers. The study 
took place in January 2017 as part of the workers' annual medical visits.

\subsection{Description of the Workplace}

The study took place in one cotton seed oil mill in the south of Benin. The mill has two parts: an in-line production area and an administrative area. The line production area has many personal workstations. Throughout the line production area, there are traces of cottonseed dust, but it is more prominent in silage, shoveling, heating. Workers in the laboratory, extraction, neutralization, decolorization, and deodorization areas may also be exposed to chemicals such as hexane by inhalation, despite the presence of a negative air pressure system used when handling this product. In the mill, there were two types of workers, casual and permanent. The casual workers were dependent on another company that had a contract with the mill. The permanent workers were directly responsible to the factory management. Our study was limited to permanent workers. In the assembly line sector, permanent workers changed workplaces after a certain period of time, with the exception of laboratory workers who changed only within the laboratory. The two main respiratory exposures in the production sector were cottonseed dust and chemicals. Production line workers were also exposed to machine noise, which can accelerate lung disease. Production workers worked in rotating shifts: 7 a.m. to 3 p.m.; 3 p.m. to 11 p.m.; 11 p.m. to 7 a.m. They worked as technicians in the laboratory, electricity, mechanics, etc. The workers in the administrative sector were not directly exposed to cotton dust or chemicals. Some of them worked in offices as accountants, financiers, secretaries, administrators; the others were clerks, drivers, storekeepers, etc. Most of them worked during normal daylight hours.

\subsection{Study Population}

A census was done. The inclusion criteria were: have a permanent contract with the mill, have age $\geq 18$ years; to be in the mill since 2 years.

\subsection{Data Collection}

All workers were interviewed. A structured questionnaire was administered in a face-to-face interview to collect demographic data, work history, respiratory symptoms (cough, phlegm, wheezing, and shortness of breath), and smoking history. Workers who reported respiratory symptoms were defined as symptomatic, and those with no respiratory symptoms were defined as asymptomatic. For smoking history, workers were classified into smokers (current and ex-smoker) and nonsmokers. A physical examination was performed to collect vitals (oxygen saturation, weight, height, blood pressure) and pulmonary auscultation disturbances. Body mass index (BMI) was calculated and classified as normal, overweight and obese. Lung function tests (LFTs) were performed by a qualified physician using a portable spirometer (MIR Spirobank II) according to the recommendations of the American Thoracic Society [6]. A minimum of three acceptable tests were 
performed on each worker. A test was defined as acceptable if the worker showed no signs of hesitation at the start of the measurement, did not cough or hesitate during the maneuvers, there was no leakage from the mouthpiece, and the exhalation lasted at least 6 seconds. Spirometry measures concerned: Forced expiratory volume (FEV1); Forced vital capacity (FVC), Forced expiratory flow at 25\% and 75\% (FEF25-75\%); Point expiratory flow (PEF). Spirometry results were interpreted by an occupational physician and a pulmonologist. The ventilatory disorders were defined by comparing the spirometry measurements before the start of work with the upper and lower limit values of the theoretical value. Thus we distinguish:

Normal spirometry: LIN $\leq$ FEV $1 \leq \mathrm{ULN}$ and $\mathrm{LIN} \leq \mathrm{CVF} \leq \mathrm{ULN}$ and $\mathrm{LIN} \leq$ FEV1/CVF $\leq$ ULN;

An obstructive ventilatory disorder (OVD): FEV1/FVC $<$ LIN and LIN $\leq$ FVC $\leq \mathrm{ULN}$;

A probable restrictive ventilatory disorder (RVD): FVC $<$ LIN and LIN $\leq$ FVC $\leq$ LSN;

A probable mixed ventilatory disorder (MVD) which is a combination of probable obstructive and restrictive ventilatory disorders.

A pulmonary X-ray was done to each worker. The investigator responsible for the radiological interpretation had no knowledge of the exposure state of the test subjects.

\subsection{Statistical Methods}

The entire process was carried out in the same way during data collection. Data were entered and analyzed using Epidata software. Significance of univariate differences was assessed by the chi-squared test for categorical variables. A P-value of 0.05 was considered significant.

\subsection{Ethical Considerations}

Free and informed consent was obtained from the workers before their inclusion in the study. The data were treated anonymously and confidentially. The study was conducted in accordance with the principles of the Helsinki Declaration.

\section{Results}

\subsection{Characteristics of Workers}

A total of 52 permanent workers were included among the 58 workers of the mill. Six permanent workers were not included because do not meet inclusion criteria. The majority, 43 (83\%) of workers were male. The average age was 42.7 \pm 6.4 years. Almost half of the workers; 27 (52) was older than 42 years. A total of $30(58 \%)$ were in technical production positions versus $22(42 \%)$ in administrative positions. Most of them; 29 (56\%) had more than 10 years of seniority. Regarding work schedules, $38.5 \%$ of the workers worked rotating shifts and $61.5 \%$ worked regular day shifts. As clinical history it was found in 30 pro- 
duction workers vs. 22 administration workers the following health problems; smoking 1 vs. 0 ; overweight 14 (46.6) vs. 13 (59); hypertension 6 (20) vs. 6 (27.2); atopic 7 (23.3) vs. 10 (45.5). Table 1 presents characteristics of the workers interviewed.

\subsection{Respiratory Symptoms}

The prevalence of respiratory symptoms was $6(11.5 \%)$ represented mainly by cough: 4 (7.7\%); chest pain: 3 (5.7\%) and dyspnea: 2 (3.8\%), phlegm: 1 (2\%). The

Table 1. Characteristics of cottonseed oil mill workers, Bénin, 2017; $(\mathrm{N}=52)$.

\begin{tabular}{|c|c|c|c|}
\hline & $\begin{array}{l}\text { Production } \\
\text { Workers } \\
\mathrm{N}=30 \\
(\mathrm{n}, \%)\end{array}$ & $\begin{array}{l}\text { Administration } \\
\text { Workers } \\
\begin{array}{c}\mathrm{N}=22 \\
(\mathrm{n}, \%)\end{array}\end{array}$ & $\begin{array}{c}\text { Total } \\
\mathrm{N}=52 \\
(\mathrm{n}, \%)\end{array}$ \\
\hline \multicolumn{4}{|l|}{ Age } \\
\hline$<42$ years & $12(40)$ & $13(59)$ & $25(48)$ \\
\hline$\geq 42$ years & $18(60)$ & $9(36)$ & $27(52)$ \\
\hline \multicolumn{4}{|l|}{ Sex } \\
\hline Male & $27(90)$ & $16(72.7)$ & $43(83)$ \\
\hline Female & $3(10)$ & $6(27.3)$ & $9(17)$ \\
\hline \multicolumn{4}{|l|}{ Smoking habit } \\
\hline Never smoking & $29(96.6)$ & $22(100)$ & $51(98)$ \\
\hline Current or ex-smoker & $1(3.4)$ & 0 & $1(2)$ \\
\hline \multicolumn{4}{|l|}{ Duration of employment } \\
\hline$<10$ years & $11(36.6)$ & $12(54.5)$ & $23(44)$ \\
\hline$\geq 10$ years & $19(63.3)$ & $10(45.5)$ & $29(56)$ \\
\hline \multicolumn{4}{|l|}{ Shift work } \\
\hline Yes & $0(0)$ & $20(90.9)$ & $20(38.5)$ \\
\hline No & $30(100)$ & $2(9.09)$ & $32(61.5)$ \\
\hline \multicolumn{4}{|l|}{$\operatorname{IMC}\left(\mathrm{kg} / \mathrm{m}^{2}\right)$} \\
\hline$<25$ & $17(56.6)$ & $8(36)$ & $25(48)$ \\
\hline$\geq 25$ & $14(46.6)$ & $13(59)$ & $27(52)$ \\
\hline \multicolumn{4}{|l|}{ HTA } \\
\hline Yes & $6(20)$ & $6(27.2)$ & $12(23)$ \\
\hline No & $24(80)$ & $16(72.7)$ & $40(77)$ \\
\hline \multicolumn{4}{|l|}{ Atopie } \\
\hline Yes & $7(23.3)$ & $10(45.4)$ & $17(33)$ \\
\hline No & $23(76.6)$ & $12(54.5)$ & $35(67)$ \\
\hline
\end{tabular}

${ }^{*} \mathrm{P}<0.05$. 
Table 2. Prevalence of respiratory symptoms of cottonseed oil mill workers, Bénin, 2017; $(\mathrm{N}=52)$.

\begin{tabular}{|c|c|c|c|c|c|c|}
\hline & $\begin{array}{l}\text { Cough } \\
\text { n (\%) }\end{array}$ & $\begin{array}{l}\text { Phlegm, } \\
\text { n (\%) }\end{array}$ & $\begin{array}{c}\text { Dyspnea } \\
\text { n (\%) }\end{array}$ & $\begin{array}{c}\text { Chest pain } \\
\mathrm{n}(\%)\end{array}$ & $\begin{array}{l}\text { Any pulmonary } \\
\text { symptom n (\%) }\end{array}$ & $\begin{array}{l}\mathrm{SaO}_{2}<95 \% \\
\text { n }(\%)\end{array}$ \\
\hline All workers (52) & $4(7.7)$ & $1(2)$ & $2(3.8)$ & $3(5.7)$ & $6(11.5)$ & $4(7.7)$ \\
\hline \multicolumn{7}{|l|}{ Type of work } \\
\hline Production $(\mathrm{n}=30)$ & $4(13)$ & $1(3.2)$ & $1(3.2)$ & $1(3.2)$ & $4(13)$ & $2(6.5)$ \\
\hline Administration $(\mathrm{n}=22)$ & 0 & 0 & $1(4.5)$ & $2(9)$ & $2(9)$ & $2(9)$ \\
\hline \multicolumn{7}{|l|}{ Age } \\
\hline$<42$ years $(\mathrm{n}=25)$ & $2(8)$ & $1(4)$ & $1(4)$ & $3(12)$ & $4(16)$ & $2(8)$ \\
\hline$\geq 42$ years $(n=27)$ & $2(7)$ & 0 & $1(3.7)$ & 0 & $2(7)$ & $2(7.4)$ \\
\hline \multicolumn{7}{|l|}{ Duration of employment } \\
\hline$<10$ years $(\mathrm{n}=23)$ & $2(8.6)$ & $1(4.3)$ & $1(4.3)$ & $3(13)$ & $4(17.4)$ & $1(4.3)$ \\
\hline$\geq 10$ years $(n=29)$ & $2(7)$ & 0 & $1(3.5)$ & 0 & $2(7)$ & $3(10)$ \\
\hline \multicolumn{7}{|l|}{ Hypertension } \\
\hline Yes $(n=12)$ & 0 & 0 & $1(8.3)$ & 0 & $1(8.3)$ & $2(16.6)$ \\
\hline No $(\mathrm{n}=40)$ & $4(10)$ & 0 & $1(2.5)$ & $3(7.5)$ & $5(12.5)$ & $2(5)$ \\
\hline \multicolumn{7}{|l|}{ IMC } \\
\hline$<25(\mathrm{n}=25)$ & $3(12)$ & $1(4)$ & $1(4)$ & $2(8)$ & $5(20)$ & $3(12)$ \\
\hline$>25(\mathrm{n}=27)$ & $1(3.7)$ & 0 & $1(3.7)$ & $1(3.7)$ & $1(3.7)$ & $1(3.7)$ \\
\hline
\end{tabular}

prevalence of respiratory symptoms in production workers was 4 (13\%) compared with $2(9 \%)$ in administrative workers. There was no statistically significant difference between the presence of respiratory symptoms and factors such as age, length of service, hypertension and BMI. However, the proportions of respiratory symptoms were higher in production workers and those under 42 years of age. The typical profile of the respiratory symptomatic worker in the oil mill was a male under 42 years of age with less than 10 years of service, nonsmoker, non-hypertensive, non-obese working in the production sector. The $\mathrm{SaO}_{2}$ was abnormal (less than 95\%) in 4 (7.7\%) workers. Table 2 sums up the respiratory symptoms among cotton-seed workers

\subsection{Spirometer and Chest X-Ray Results}

Interpretation of the spirometry results showed that $38(73.1 \%)$ were completely normal, 6 (11.5\%) had mild spirometry abnormalities but were still considered to be in the normal range, and 8 (15.4\%) were clearly abnormal. Of the 8 individuals with abnormal spirometry, 4 had an obstructive syndrome, 3 had a restrictive syndrome, and 1 individual had a mixed pattern.

There were $5(16.6 \%)$ workers in production vs. $3(13.6 \%)$ in administration who have abnormal spirometry.

Considering the spirometry parameters separately we observed that in total, 6 
(11.5\%) of the workers had a loss of FEV1 between $5 \%$ and $10 \%$ of their theoretical values, $13(25 \%)$ a loss between $10 \%$ and $20 \%$ of FEV1 and $4(7.6 \%)$ a loss of more than $20 \%$ with no statistically significant difference according to the workplace. For the PEF, 6 (11.5\%) workers had a loss between 5\% and $10 \%$ of their theoretical values, $13(25 \%)$ a loss between $10 \%$ and $20 \%$ and $13(25 \%)$ a loss of more than $20 \%$ with no statistically significant difference according to the workplace. Regarding the FEF2575, there was a statistically significant difference between the means of production workers and administration workers. This difference is maintained despite the exclusion of subjects with a history of asthma symptoms before they began working in the company. A loss over $40 \%$ of their theoretical values was observed for 8 (15\%). After exclusion of workers with a personal history of asthma, the results were the same.

Of the 52 workers, 8 (15\%) had a chest X-ray abnormality (bronchial syndrome). Abnormal chest X-ray were 5 (17\%) in production workers compared to 3 (14\%) in administration workers. Table 3 and Table 4 summed up the results.

Table 3. Results of lung function and chest X-ray of cottonseed oil mill workers, Bénin, 2017; $(\mathrm{N}=52)$.

\begin{tabular}{|c|c|c|c|}
\hline & $\begin{array}{r}\text { Total } \\
\text { N (\%) }\end{array}$ & $\begin{array}{c}\text { Production }=30 \\
\mathrm{~N}(\%)\end{array}$ & $\begin{array}{c}\text { Administration }=22 \\
\mathrm{~N}(\%)\end{array}$ \\
\hline \multicolumn{4}{|l|}{ FEV1 } \\
\hline Mean FEV $1 \pm$ SD & $3.06 \pm 0.52$ & $3.11 \pm 0.51$ & $3.00 \pm 0.53$ \\
\hline Lost $\geq 5 \%$ FEV 1 & $23(44)$ & $14(47)$ & $9(41)$ \\
\hline Lost $\geq 10 \% \mathrm{FEV} 1$ & $17(33)$ & $10(33)$ & $7(32)$ \\
\hline Lost $\geq 20 \%$ FEV 1 & $4(7.6)$ & $2(6)$ & $2(9)$ \\
\hline \multicolumn{4}{|l|}{ PEF } \\
\hline Mean PEF \pm SD & $7.62 \pm 1.72$ & $7.72 \pm 1.62$ & $7.5 \pm 1.88$ \\
\hline Lost $\geq 5 \% \mathrm{PEF}$ & $32(61.5)$ & $20(66)$ & $12(54)$ \\
\hline Lost $\geq 10 \% \mathrm{PEF}$ & $26(50)$ & $16(53)$ & $10(45)$ \\
\hline Lost $\geq 20 \% \mathrm{PEF}$ & $13(25)$ & $9(30)$ & $4(18)$ \\
\hline \multicolumn{4}{|l|}{ FEF2575 } \\
\hline Mean FEF2575 \pm SD * & $3.16 \pm 1.05$ & $3.28 \pm 1.22$ & $3.00 \pm 0.70$ \\
\hline Lost $\geq 10 \%$ FEF 2575 & $42(80)$ & $24(80)$ & $18(82)$ \\
\hline Lost $\geq 20 \%$ FEF 2575 & $32(61.5)$ & $18(60)$ & $14(63)$ \\
\hline Lost $\geq 40 \%$ FEF 2575 & $8(15)$ & $5(17)$ & $3(14)$ \\
\hline \multicolumn{4}{|l|}{ FVC } \\
\hline Mean FVC \pm SD & $3.77 \pm 0.77$ & $3.82 \pm 0.69$ & $3.69 \pm 0.89$ \\
\hline Lost $\geq 10 \%$ FVC & $12(23)$ & $7(58.3)$ & $5(41.7)$ \\
\hline Lost $\geq 20 \%$ FVC & $4(7.6)$ & $1(3)$ & $3(13.6)$ \\
\hline
\end{tabular}


Continued

\begin{tabular}{cccc}
\hline $\begin{array}{c}\text { Troubles ventilators } \\
\text { Obstructive Syndrome }\end{array}$ & $4(7.6)$ & $2(6)$ & $2(9)$ \\
Suspicion of restrictive syndrome & $3(5.6)$ & $1(3)$ & $2(9)$ \\
Mixed Syndrome & $1(2)$ & 0 & $1(4.5)$ \\
Chest X-ray & & & \\
Normal & $44(85)$ & $25(83)$ & $19(86)$ \\
Abnormal & $8(15)$ & $5(17)$ & $3(14)$ \\
\hline
\end{tabular}

${ }^{*} \mathrm{P}<0.05$.

Table 4. Means of lung function without workers with asthma before starting job of cottonseed oil mill workers, Bénin, 2017; $(\mathrm{N}=48)$.

\begin{tabular}{cccc}
\hline & Total & $\begin{array}{c}\text { Production } \\
\mathbf{N}=\mathbf{2 8}\end{array}$ & $\begin{array}{c}\text { Administration } \\
\mathbf{N}=\mathbf{2 0}\end{array}$ \\
\hline Mean FEV1 & $3.06 \pm 0.52$ & $3.09 \pm 0.50$ & $3.03 \pm 0.53$ \\
Mean PEF & $7.75 \pm 1.68$ & $7.85 \pm 1.59$ & $7.62 \pm 1.84$ \\
$*$ Mean Fef2575 & $3.29 \pm 0.99$ & $3.41 \pm 1.15$ & $3.11 \pm 0.69$ \\
Mean CVL & $3.72 \pm 0.74$ & $3.80 \pm 0.70$ & $3.62 \pm 0.79$ \\
\hline
\end{tabular}

${ }^{*} \mathrm{P}<0.05$.

\section{Discussion}

This study is the first to explore respiratory disorders in cottonseed oil mill workers in Benin. Its limitation is the inclusion of only permanent workers because of their accessibility, not taking into account casual workers despite the fact that they are more exposed to cotton dust because of the tasks they are assigned.

The prevalence of respiratory symptoms was higher in production workers than in administrative workers, with no statistically significant difference between them. This result is similar to that of Bakirci $\mathrm{N}$ et al. in Turkey, who found no statistically significant difference in the prevalence of respiratory symptoms in workers exposed to cotton dust in an oil mill compared to a group of non-exposed workers [6]. However, the overall prevalence of respiratory symptoms was higher $(50 \%)$ than ours $(11.5 \%)$. The prevalence of respiratory symptoms such as cough, phlegm, dyspnea obtained in this study were all lower than those observed by Ade et al. [11] in ginning mills in northern Benin, and Hinson et al. in textile mills in the same country [10].

The difference between the prevalence of symptoms in workers exposed to cotton dust but in different sectors: ginning, oil mills, textiles is certainly related to the production processes and the level of exposure to cotton dust. Indeed, the textile sector remains the most at risk due to exposure to finer particles. In this study, the level of exposure to airborne contaminants differs according to the 
type of workplace. In addition, the current workers, being all permanent employees, are more in a supervisory position than in a position of performing different tasks and subtasks.

The total prevalence of ventilatory disorders (obstructive, restrictive and mixed) was $15.4 \%$, with no significant difference by workplace. This prevalence is low compared to the $26.9 \%$ obtained by Ade et al. in ginning mills [11]. In the study of Hinson et al., $44 \%$ of the workers in the textile sector had a loss of more than $20 \%$ of FEV 1 compared to $9 \%$ in our study [10]. These differences are explained by the types of processes in each sector.

The mean values of spirometry parameters such as FEV1, PEF and FVC are similar in the production and administration sectors, with the exception of FEF2575 which is lower in production workers compared to administration workers. The degree of loss also appears to be similar in the two groups. This result is not expected and reflects the fact that administrative workers are not good comparators in this study because they share the same general work environment as production workers. Indeed, many studies have shown the direct effect of cotton dust exposure in the decline of ventilatory functions and the development of byssinosis [12] [13]. On the other hand, for some, in the case of oil mills, "cotton dust" is not necessarily a "byssinogenic" dust, but it is capable of producing effects on ventilatory functions similar to those produced by cotton fiber dust [14]. A future large-scale study including casual workers is important to further explore this issue in cottonseed oil mill workers in Benin.

\section{Conclusion}

Oil mill workers show few respiratory symptoms. However, workers in the production sector have more ventilatory problems than those in administration. Therefore, spirometry monitoring of this group of workers is necessary.

\section{Acknowledgements}

Our thanks go to the managers and workers of the oil mill.

\section{Conflicts of Interest}

The authors declare no conflicts of interest regarding the publication of this paper.

\section{References}

[1] Driscoll, T., Steenland, K., Nelson, D.I. and Leigh, J. (2004) Occupational Airborne Particulates: Assessing the Environmental Burden of Disease at National and Local Levels. Environmental Burden of Disease Series, No. 7.

[2] Dube, K.J., Ingale, L.T., Ingle, S.T., Dube, K.J. and Ingale, L.T. (2013) Respiratory Impairment in Cotton-Ginning Workers Exposed to Cotton Dust. International Journal of Occupational Safety and Ergonomics, 19, 551-560.

[3] Laraqui, C.H., Rahhali, A., Laraqui, O., Tripodi, D., Curtes, J.P., Verger, C. and Caubet, A. (2002) Byssinosis and Occupational Asthma among Cotton Dust-Exposed 
Workers. Revue Française d'Allergologie et d'Immunologie Clinique, 42, 133-141. https://doi.org/10.1016/S0335-7457(01)00127-7

[4] Tabak, S., Broday, D.M., Tabak, I. and Manor, G. (2002) Occupational Exposure to Cotton Dust in Cottonseed Oil Mills. Applied Occupational and Environmental Hygiene, 17, 121-130. https://doi.org/10.1080/104732202317201366

[5] Zey, J.N., Piacitelli, G.M. and Jones, W.G. (1984) Characterization of Airborne Cotton Dust Concentrations in the Non-Textile Cotton Industry. American Industrial Hygiene Association Journal, 45, 538-546. https://doi.org/10.1080/15298668491400232

[6] Bakirci, N., Sayiner, A., Sacaklioglu, F. and Bayindir, U. (2006) Across-Shift Lung Function Variation in Cottonseed Oil Workers. Occupational Medicine, 56, 365-370. https://doi.org/10.1093/occmed/kq1033

[7] Jones, R.N., Carr, J., Glindmeyer, H., Diem, J. and Weill, H. (1997) Respiratory Health and Dust Levels in Cottonseed Mills. Thorax, 32, 281-286. https://doi.org/10.1136/thx.32.3.281

[8] Uzma, N, Salar, B.M.K.M., Santhosh Kumar, B., Aziz, N., David, M.A. and Reddy, V.D. (2008) Impact of Organic Solvents and Environmental Pollutants on the Physiological Function in Petrol Filling Workers. International Journal of Environmental Research and Public Health, 5, 139-146. https://doi.org/10.3390/ijerph5030139

[9] INRS (2019) Fiche Toxicologique ${ }^{\circ} 113$. Hexane, 1-15.

[10] Hinson, A.V., Lokossou, V.K., Schlünssen, V., Agodokpessi, G., Sigsgaard, T. and Fayomi, B. (2016) Cotton Dust Exposure and Respiratory Disorders among Textile Workers at a Textile Company in the Southern Part of Benin. International Journal of Environmental Research and Public Health, 13, Article No. 895. https://doi.org/10.3390/ijerph13090895

[11] Ade, S., Adjobimey, M., Minankpon, B., Dovonou, A.C. and Agodokpessi, G. (2018) Prévalence et Facteurs Associés aux Troubles Fonctionnels Respiratoires chez les égreneurs du Coton dans le nord du Bénin. Revue des Maladies Respiratoires, 35, A235. https://doi.org/10.1016/j.rmr.2017.10.546

[12] Hayes, G.B., Ye, T.T., Lu, P.L., Dai, H.L. and Christiani, D.C. (1994) Respiratory Disease in Cotton Textile Workers: Epidemiologic Assessment of Small Airway Function. Environmental Research, 66, 31-43. https://doi.org/10.1006/enrs.1994.1042

[13] Wang, X.R., Eisen, E.A., Zhang, H.X., Sun, B.X., Dai, H.L., Pan, L.D., et al. (2003) Respiratory Symptoms and Cotton Dust Exposure; Results of a 15 Year Follow up Observation. Occupational \& Environmental Medicine, 60, 935-941. https://doi.org/10.1136/oem.60.12.935

[14] Noweir, M.H. (1981) Some Observations on Epidemiologic Studies in Egyptian Gins, Cotton Pressing Plants and Cottonseed OIL extraction Plants. Chest, 79, 15S-20S. https://doi.org/10.1378/chest.79.4 Supplement.15S 


\section{Appendices}

$\mathrm{N}^{\bullet}$ Questions

\section{General information}

Q1 Record number

Q2 Date of registration

Q3 Personnel number

Q4 Phone number

\section{Socio-demographic characteristics}

Q5 Age (Years)

Q6 Sex

Q7 Nationality

Q8 Marital status

Q13 Level of education
Codes

Answer

Date of registration in the study

Give the participant's registration number in the structure

Number of years completed

Female $=0 ;$ Male $=1$

Beninese $=0 ;$ Others $=1($ Specify.............$)$

Single $=0 ;$ Couple $=1 ;$ Divorced $=2 ;$

Widowed $=3$

Never attended $=0$; Literate $=1$; Primary $=2$;

Secondary $=3$; Higher $=4$

\section{Workplace information and associated respiratory risks}

Q9 How many years have you been working in the oil mill?

Q10 What is your workstation

Q11 The worker is involved in which area of the oil mill?

Q12 Is the worker exposed to inhalation of cotton dust?

Q13 Is the worker exposed to hexane inhalation?

No $=0 ;$ Yes $=1$
Specify the number of years of exercise; 999 if not applicable

Administration $=0$; Production $=1$
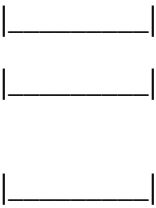

History and use of drugs

Q14 What is your smoking status?

Q15 Number of years of smoking (Current or former smoker)

Q16 Number of IPs (Current or Former Smoker)

Q17 Do you use other drugs such as cannabis or cocaine?

\section{Complaints}

Q18 Do you have a frequent cough?

Q19

What are the common characteristics of this cough?
No $=0 ;$ Yes $=1$

Non-smoker $=0$; Current smoker $=1$;

Ex smoker $=2$; Passive smoker $=3$

No $=0 ;$ Yes $=1$

Acute cough $=0$; Chronic dry cough $=1$; Chronic productive cough $=2 ;$ Not applicable $=9$ 


\section{Continued}

Q20 Do you have frequent Phlegm?

Q21 Do you have frequent chest pain?

Q22 Do you frequently experience breathing difficulties?

Q23 Staging of dyspnea (Sadoul scale)

$$
\begin{aligned}
& \text { No }=0 ; \text { Yes }=1 \\
& \text { No }=0 ; \text { Yes }=1 \\
& \text { No }=0 ; \text { Yes }=1
\end{aligned}
$$

Stage $0=0$; StageI $=1$; StageII $=2$;

StageIII $=3 ;$ StageIV $=4 ;$ StageV $=5 ;$ Unknown $=9$

Q24 Do you have frequent wheezing in your chest? No $=0$; Yes $=1$

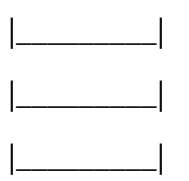

Q25 Do you have frequent hemoptysis?

Q26 How many years have you had these symptoms regularly?

\section{General review}

Q27 Weight (kgs)

Q28 Size $(\mathrm{cm})$

Q29 Body mass index $\left(\mathrm{kg} / \mathrm{m}^{2}\right)$

Q30 Systolic blood pressure $(\mathrm{mmHg})$

Q31 Diastolic blood pressure ( $\mathrm{mmHg}$ )

Q32 Heart rate (/ min)

Q33 Respiratory rate (/ $\mathrm{min})$

Q34 $\mathrm{SaO}_{2}$

\section{Physical examination}

Q34 Pleuro-pulmonary examination

Q35 Specify abnormality if abnormal pleuropulmonary examination

\section{Spirometry results}

Q36 Measured FEV1 (L)

Q37 LIN Theoretical FEV1 (L)

Q38 Measured FEV1/Theoretical FEV1

Q39 Measured FVC (L)

Q40 LIN Theoretical FVC (L)

Q41 FEV1/FVC measured (\%)

Q42 FEV1/Theoretical FVC LIN (\%)

Q43 Result of spirometry
No $=0 ;$ Yes $=1$

Normal $=0 ;$ Abnormal $=1$
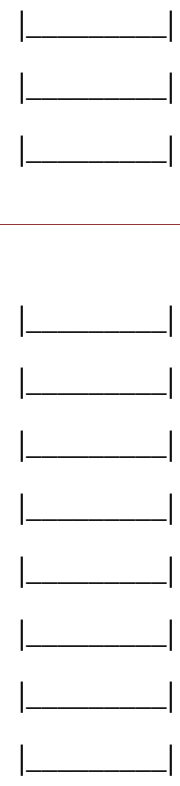